\title{
HUMAN RESOURCE MANAGEMENT IN THE ORGANIZATION
}

\section{TASAVVUR MALIK}

Research Scholar, Department of Management, Glocal University, Saharanpur, Uttar Pradesh, India

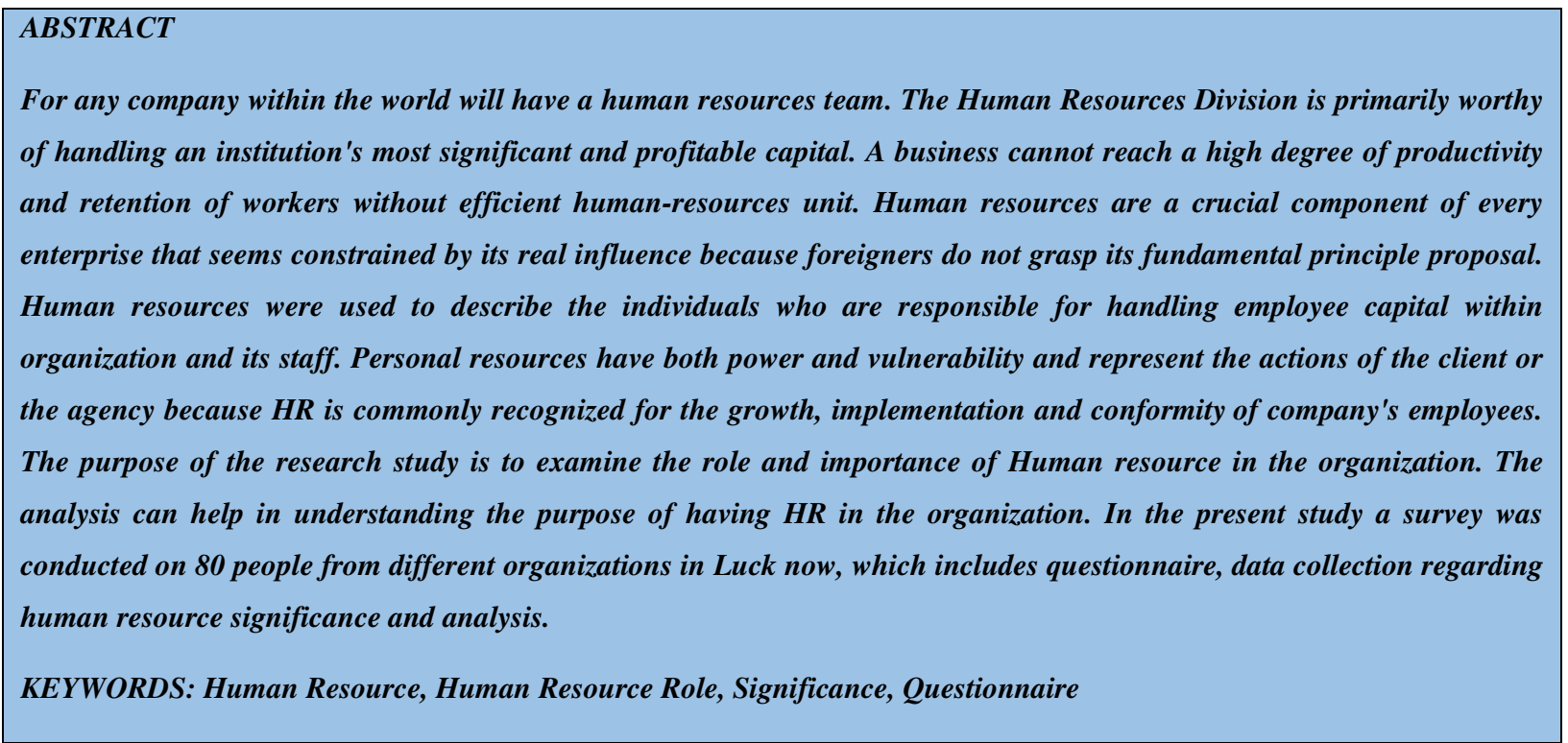

Received: Jun 08, 2020; Accepted: Jun 28, 2020; Published: Sep 08, 2020; Paper Id.: IJMPERDJUN20201111

\section{INTRODUCTION}

The financial capital of business that includes the staff agency, an industry economy. Each organization has a strategy to its objective by effective usage of resources. It may also be used with equipment, supplies and resources as a development element. As usual as the consistency of Armstrong's research is among the key leading factors of performance or failure. We recognize the requirement in new global market the presence of an exponentially expanded human capital.

William R. Tracey describes Human resource as "the men who live and operate" as opposed to a company's monetary and material capital. Human capital is an advantage, most commonly utilized integral concept to achieve the organization's full efficiency[1]. Power human capital is the sustained growth and eventual market success in technology based industries.

The human capital framework is the main competitive considerations for an organization's performance which helps to highlight human resources management's developmental vision and long-term dimension.

Human resource plays an important role in building the organization which includes many steps such as:

\subsection{Recruitment Process}

The recruiting of fresh employees will help make any company sustainability. The Division of Human Resources requires a good view of positions found within a company and takes reasonable steps to fill such 
positions. It's a long process to hire fresh employees. This is related to the release of potential career lovers, the identification of suitable recruits, evaluating applications, holding surveys in preliminary process and organizing the final decision-makers.

\subsection{Building Employees Relationship}

Within a unionized workplace climate, the HR team is accountable for establishing partnerships with workers. The emphasis is also on improving workplace ties. It helps HR team to settle all kinds of issues within the company.

\subsection{Provide Employees Safety}

Specific consideration will be given to occupational health across all organizations. For having a secure working atmosphere for workers, HR team implements the appropriate steps. This also tracks casualties that are further addressed to upper managers inside the company.

\subsection{Providing Sake and Reimbursement to Employees}

All of the experts in HR team is liable for salaries and the services that can be offered to workers. The entity also assesses fair compensation strategies.

\subsection{Training and Development}

Appropriate instruction will be given to all workers inside an organization. The human resources team is accountable for supplying all workers with appropriate preparation and growth. In addition to comprehensive induction preparation, the bulk of HR teams around the globe aim to provide the staff with career advancement and leadership instruction. It allows workers to adjust within atmosphere of the company and to reach optimum growth capacity.

In all portion of the country, hierarchical framework of HR is moreover similar. But in large organizations, including HR back room, HR offices, the group is split into many levels. The HR Boss manages the whole team. There should be more than one boss of broad organizations. The leaders are responsible for executing HR policy and company plan. Management also recommends that HR systems be properly executed.HR's organizational frame must be simple[2]. In addition, the dept's lowest parts should be provided responsibility for decision-making. HR practitioners should therefore significantly deliver to company's development. If so many administrators remain, policy taking may get delayed, and the organization's intended plans may not executed in due time. At other side, HR can be agile as well in its corporate framework. The HR managers could then fastly adapt to organization's specific criteria.

\subsubsection{Human Resources Also Involves Different Posts Which Includes:}

HR Manager: HR executives are highest in field of operational framework. HR executives are accountable for guiding HR teams down correct path and having them execute an HR plan that will have an effect on enterprise as a whole.

Generalist: The task of generalists is to meet with company's top managerial dept. to execute a corporate plan. General staff must always collaborate with their colleagues to solve all minor problems which occur during day-to-day collaborate. The position of HR Generalist may also be sub-categorized into different divisions. These involve HR manager, HR staff and HR trainees.

Employment Manager: It should be used as several of key positions of human resources team. The recruiting officer is responsible for assessing if a particular candidate blends in into the corporate environment. For certain instances 
they may even serve as advisors.

\section{REVIEW OF LITERATURE}

Many researches have examined the correlation among human resources management and foundation's success with reasonably helpful outcomes. Nevertheless, the emphasis of current work in such field has moved from examining the connection among different approaches for management of human resources and organizations' results to figuring out how strategies for human resources management impact the organization's efficiency. The same opinion is still taken by Boselie et al[3].

Aforementioned relationship has also been tested by Collins and Smith[4]. Likewise, Hailey et al. also showed the same findings. However, the findings of such experiments are distorted by recent work into the correlation within HRM's activities and foundation's results[5]. Such studies suggest that there is appropriate starting point for assertion of consistent and constructive association among human resource managing activities and success of organization. When the viewpoint of social interaction is used, workers responded to behavior of the company.

Druker, gave an opinion that to increase the efficiency of operation of human capital for generating value for business, workers ought to be fulfilled, paid, reviewed of transparent contact mechanisms need to be created and therefore the ultimate enterprise will provide input. This means that organization's staff are already happy and business performs[6].

Huselid and colleagues consider that procedures of human resources play important role within the company's service outcome[7].Pfeffer and colleagues also over-viewed that business success depends on how organization tackles its staff members and involve 7 human resources procedures that incorporate organizationrelation with staff members.Barney and colleagues address one method of recruiting, keeping and empowering workers, is to utilize a different approach to achieve comparative edge. Their points are also based primarily on common human resources activities[8].

As per Yoon and colleagues, business activities in 2002 include employees' feelings as well as their way of thinking, which includes employees, indicating that agency handles the workers taking appropriate steps on employee issues[9]. Human resource development concerns are sometimes evaluated, in way of Sheppeck and colleagues, as they are concerned with the way in which organizations deal with their human capital and concentrate on operations of various and indicators[10].

Strategic experts in handling human capital depend extensively over databases of organizations to evaluate the effect of policies in area of human resources on business success[11]. Theoretical studies on human resources have nevertheless suggested that human resources activities that improve the company's efficiency and may become a special means as activities are often ineffective, causally ambiguous and impossible to replicate (Lado\& Wilson, 1994).

Nevertheless, Wright et al. claimed that activities of human resources will help to build a competitive specific advantage in terms of expertise or abilities, and add benefit for enterprise. Wright et al., 2001 and other scholars have also addressed the value of tools for SHRM analysis that are vital to competitive advantage of the organization[12].

\section{METHODOLOGY}

\subsection{Design}

In this approach, a room was selected wherein employees from different organizations of Lucknow were gathered and the survey was conducted. The survey includes a questionnaire which includes sequence of questions regarding the human resource. The questionnaire involves objective type questions with options, depending on the type of the questions. The survey was conducted for $2.5 \mathrm{hrs}$ and all the favorable conditions in the examination hall were provided. The survey was 
carried over 400 individuals. After the examination, the data was analyzed and conclusion was made regarding the response of the participants.

\subsection{Sample}

The survey involved planned questionnaires to gather details regarding importance of human resource in the organization, 80 participants which include 10 employees from each organization. In this survey participants were from 8 different organizations.

\subsection{Instrument}

Questions Raised in the Survey Includes as Follows: (Table 1)

Table 1: Questionnaire Regarding Importance of HR in the Organization

\begin{tabular}{|c|c|c|}
\hline \multirow{2}{*}{1 . } & \multirow{2}{*}{ Is the HR of your organization is able to manage things? } & Yes \\
\hline & & No \\
\hline \multirow{2}{*}{2 . } & \multirow{2}{*}{ Does HR have ethics in accordance with the company? } & Yes \\
\hline & & No \\
\hline \multirow{2}{*}{3.} & \multirow{2}{*}{ Is the HR able to balance relationship between employee and employers? } & Yes \\
\hline & & No \\
\hline \multirow{2}{*}{4.} & \multirow{2}{*}{ Is the HR able to solve problems arising in the organization and aids in organization's growth? } & Yes \\
\hline & & No \\
\hline \multirow{2}{*}{5 . } & \multirow{2}{*}{ Does the HR possess expertize in accordance with companies guidelines? } & Yes \\
\hline & & No \\
\hline & \multirow{2}{*}{$\begin{array}{l}\text { Does the HR possess leadership qualities in concern of the employees i.e. is it able to solve the } \\
\text { employee concern? }\end{array}$} & Yes \\
\hline & & No \\
\hline
\end{tabular}

\subsection{Data Collection and Analysis}

Based on the response generated by the participants, the data was collected for further analysis which is discussed below.

\subsubsection{Is the HR of Your Organization is Able to Manage Things?}

Table 2

\begin{tabular}{|c|c|c|}
\hline Organization & \multicolumn{2}{|c|}{ Response } \\
\hline & Yes & No \\
\hline Organization 1 & $\checkmark$ & \\
\hline Organization 2 & $\checkmark$ & \\
\hline Organization 3 & & $\checkmark$ \\
\hline Organization 4 & $\checkmark$ & \\
\hline Organization 5 & $\checkmark$ & \\
\hline Organization 6 & $\checkmark$ & \\
\hline Organization 7 & & $\checkmark$ \\
\hline Organization 8 & & $\checkmark$ \\
\hline
\end{tabular}

\subsubsection{Does HR Have Ethics in Accordance with the Company?}

Table 3

\begin{tabular}{|c|c|c|}
\hline Organization & \multicolumn{2}{|c|}{ Response } \\
\hline & Yes & No \\
\hline Organization 1 & $\checkmark$ & \\
\hline Organization 2 & $\checkmark$ & \\
\hline Organization 3 & $\checkmark$ & \\
\hline Organization 4 & $\checkmark$ & \\
\hline Organization 5 & $\checkmark$ & \\
\hline
\end{tabular}




\begin{tabular}{|c|c|c|}
\hline Organization 6 & & $\checkmark$ \\
\hline Organization 7 & & $\checkmark$ \\
\hline Organization 8 & $\checkmark$ & \\
\hline
\end{tabular}

3.4.3. Is the HR Able to Balance Relationship between Employee and Employers?

Table 4

\begin{tabular}{|c|c|c|}
\hline Organization & \multicolumn{2}{|c|}{ Response } \\
\hline & Yes & No \\
\hline Organization 1 & $\checkmark$ & \\
\hline Organization 2 & $\checkmark$ & \\
\hline Organization 3 & $\checkmark$ & \\
\hline Organization 4 & & $\checkmark$ \\
\hline Organization 5 & $\checkmark$ & \\
\hline Organization 6 & $\checkmark$ & \\
\hline Organization 7 & $\checkmark$ & \\
\hline Organization 8 & & $\checkmark$ \\
\hline
\end{tabular}

3.4.4. Is the HR Able to Solve Problems Arising in the Organization and Aids in Organization's Growth?

Table 5

\begin{tabular}{|c|c|c|}
\hline Organization & \multicolumn{2}{|c|}{ Response } \\
\hline & Yes & No \\
\hline Organization 1 & $\checkmark$ & \\
\hline Organization 2 & $\checkmark$ & \\
\hline Organization 3 & $\checkmark$ & \\
\hline Organization 4 & $\checkmark$ & \\
\hline Organization 5 & $\checkmark$ & \\
\hline Organization 6 & $\checkmark$ & \\
\hline Organization 7 & $\checkmark$ & \\
\hline Organization 8 & & $\checkmark$ \\
\hline
\end{tabular}

3.4.5. Does the HR Possess Expertise in Accordance with Company's Guidelines?

Table 6

\begin{tabular}{|c|c|c|}
\hline Organization & \multicolumn{2}{|c|}{ Response } \\
\hline & Yes & No \\
\hline Organization 1 & $\checkmark$ & \\
\hline Organization 2 & $\checkmark$ & \\
\hline Organization 3 & $\checkmark$ & \\
\hline Organization 4 & $\checkmark$ & \\
\hline Organization 5 & $\checkmark$ & \\
\hline Organization 6 & $\checkmark$ & \\
\hline Organization 7 & & $\checkmark$ \\
\hline Organization 8 & & $\checkmark$ \\
\hline
\end{tabular}

3.4.6. Does the HR Possess Leadership Qualities in Concern of the Employees i.e. is it Able to Solve the Employee Concern?

Table 7

\begin{tabular}{|c|c|c|}
\hline Organization & \multicolumn{2}{|c|}{ Response } \\
\hline & Yes & No \\
\hline Organization 1 & $\checkmark$ & \\
\hline Organization 2 & $\checkmark$ & \\
\hline Organization 3 & $\checkmark$ & \\
\hline Organization 4 & $\checkmark$ & \\
\hline
\end{tabular}




\begin{tabular}{|c|c|c|}
\hline Organization 5 & $\checkmark$ & \\
\hline Organization 6 & $\checkmark$ & \\
\hline Organization 7 & $\checkmark$ & \\
\hline Organization 8 & & $\checkmark$ \\
\hline
\end{tabular}

\subsection{Data Analysis}

Data collected from every participant was further analyzed and then an inference is drawn regarding the response from the participants. It was observed that, when the participants were asked about managerial skills of the HR then $70 \%$ of then agreed and $30 \%$ were not agreed. Further, when the participants were asked about ethical skills of the HR it was observed that, $80 \%$ of them agreed and rest did not agreed. Similarly questions involving balancing relationship between employee and employers, $85 \%$ agreed, however $15 \%$ didn't agreed. When the participants were asked about organization problem solving $90 \%$ agreed while $10 \%$ didn't agreed. Also, in terms of expatriation $80 \%$ people agreed while $20 \%$ disagreed. Also, $85 \%$ participants agreed that the HR of their company possess leadership qualities and $15 \%$ did not.

\section{RESULTS \& DISCUSSIONS}

\subsection{Is the HR of Your Organization is Able to Manage Things?}

The desire to remain coordinated is the critical qualities of human resources practitioners. The HR should possess capacity to control resources and execute activities effectively. The HR should be able to balance various activities, from training and development, personal concerns of employees, and selection processes for job vacancies. Multitasking and selfdiscipline are crucial parameters for HR. Ethical and behavior practices should be there and ensure that others implement them too. HRs set time constraints and execute assignments efficiently, ensuring that staff and managers are willing to satisfy their expectations.

On asking the participants about whether the HR of their organization is able to manage things, it was observed that, $70 \%$ of participants were in favor while and $30 \%$ denied.

\subsection{Does HR Have Ethics in Accordance with the Company?}

Company's HR team reflects the awareness in several respects. In order to include classified details and obey client rules, HR would require a good perception of ethics. Personnel professionals must receive confidence of staff and managers to perform one`s job adequately; sincerity and discernment are key elements of every successful human resources department.

On asking the participants about does HR have ethics in accordance with the company, it was observed that, $80 \%$ of participants agreed while $20 \%$ did not agreed.

\subsection{Is the HR Able to Balance Relationship between Employee and Employers?}

All HR practitioners have a primary role to promote contact among employers and workers. This ensures oral and written technical skills will be reliable such that knowledge may be conveyed to staff at every positions effectively and efficiently. Negotiation often requires some of contact criteria. HR professionals may support negotiate and reach the procurement phase, even where there occur disputes between workers

On asking the participants about, whether the HR of their organization has ability to balance relationship between employee and employers, $85 \%$ of participants agreed, however $15 \%$ of them didn't agreed. 


\subsection{Is the HR Able to Solve Problems Arising in the Organization and Aids in Organization's Growth?}

The HR team will insure that people of diverse backgrounds operate collectively amicably and achieve client objective for running business in best possible manner. Being HR specialist, they should be prepared to navigate crisis resolution and disseminate stressful or battle conditions for performing many duties.

On asking the participants about whether the HR of their company are able to solve problems arising in the organization and aids in organization's growth it was seen analyzed that $90 \%$ of participants were in favor while $10 \%$ did not.

\subsection{Does the HR Possesses Expertise in Accordance with Company's Guidelines?}

Leaders in company's field are good HR practitioners since it leads to better recruiting and management choices and to provide a background for organization policy and guidance. This is also quick to neglect the reality that human resources practitioners are often industry professionals.

On asking the participants about does the HR possess expertize in accordance with companies guidelines, it was observed that, $80 \%$ people agreed while $20 \%$ disagreed.

6.6. Does the HR Possess Leadership Qualities in Concern of the Employees i.e. is it Able to Solve the Employee Concern?

For several ways, workers are searching for guidance and direction from HR experts. Many positions are characterized by the fact that HR is seen as expert on large range of business-related issues. This can help from having the solution to employees concerns to creating a group to run a regional $6 \mathrm{~K}$ charity competition. The most trained HR practitioners will combine a welcoming workplace atmosphere with a command and smoother working. On asking the participants about does the HR possess leadership qualities in concern of the employees i.e. is it able to solve the employee concern, it was observed that, $85 \%$ participants agreed that the HR of their company possess leadership qualities and $15 \%$ did not.

\section{CONCLUSIONS}

From the survey conducted, it was observed that HR serves an important role in the organization. All the participants actively participated in the survey and the response generated by them was analyzed thoroughly. Greater than 80 percent participants have agreed that to build an organization HR serves an integral part. This indicates that, human resources are perfect field for professionalism who wants to support organizations achieve their targets and fulfill their potential.

The purpose of a good organization or system relies on much ability and capable of manpower. Department of Human Resources promotes operational quality by the creation of skilled and trained practitioners. This segment involves the contribution in the workplace development agency, recruiting, publishing, advertisement, fee payment, growth of workplace, Workers' ability by good appraisal and strong interactions with staff and authorities. To every organization, Human Resources are quite relevant. The best method thus to meet its goals, human resources should be pursued within the organization.

\section{REFERENCES}

1. W. H. Reid, "Human resources," Handbook of Mental Health Administration and Management. 2013.

2. B. Vermeeren, B. Steijn, L. Tummers, M. Lankhaar, R. J. Poerstamper, and S. van Beek, "HRM and its effect on employee, organizational and financial outcomes in health care organizations," Hum. Resour. Health, 2014. 
3. P. Boselie, G. Dietz, and C. Boon, "Commonalities and contradictions in HRM and performance research," Human Resource Management Journal. 2005.

4. C. J. Collins and K. G. Smith, "Knowledge exchange and combination: The role of human resource practices in the performance of high-technology firms," Acad. Manag. J., 2006.

5. T. D. Wall and S. J. Wood, "The romance of human resource management and business performance, and the case for big science," Human Relations. 2005.

6. J. Druker and G. White, "Misunderstood and Undervalued? Personnel Management In Construction," Hum. Resour. Manag. J., 1995.

7. M. A. Huselid, "The Impact of Human Resource Management Practices On Turnover, Productivity, and Corporate Financial Performance," Acad. Manag. J., 1995.

8. J. B. Barney and P. M. Wright, "On becoming a strategic partner: The role of human resources in gaining competitive advantage," Hum. Resour. Manage, 1998.

9. J. Yoon and S. R. Thye, "A dual process model of organizational commitment: Job satisfaction and organizational support," Work Occup., 2002.

10. M. A. Sheppeck and J. Militello, "Strategic HR configurations and organizational performance," Hum. Resour. Manage, 2000.

11. P. M. Wright, B. B. Dunford, and S. A. Snell, "Human resources and the resource based view of the firm," J. Manage., 2001.

a. A. Lado and M. C. Wilson, "Human Resource Systems and Sustained Competitive Advantage: A Competency-Based Perspective," Acad. Manag. Rev., 1994. 